Duxbury, C.L., R.L. Legge, G. Paliyath, R.F. Barber, and J.E. Thompson. 1991. Alterations in membrane protein conformation in response to senescencerelated changes. Phytochemistry 30:63-68.

Farmer, E.E. and C.A. Ryan. 1992. Octadecanoid precursors of jasmonic acid activate the synthesis of wound-inducible proteinase inhibitors. Plant Cell 4:129-134.

Fobel, M., D.V. Lynch, and J.E. Thompson. 1987. Membrane deterioration in senescing carnation flowers. Plant Physiol. 85:204-211.

Gardner, H.W. 1989. How the lipoxygenase pathway affects the organoleptic properties of fresh fruit and vegetables, p. 98-112. In: D.B. Min and T.H. Smouse (eds.). Flavor chemistry of lipid foods. Amer. Oil Chem. Soc., Champaign, Ill.

Hamilton-Kemp, T.R., C.T. McCracken, Jr., J.H. Loughrin, R.A. Andersen, and D.F. Hildebrand. 1992. Effects of some natural volatile compounds on the pathogenic fungi Alternaria alternata and Botrytis cinerea. J. Chem. Ecol. 18:1083-1091.

Harber, R.M. and L.H. Fuchigami. 1986. The relationship of ethylene and ethane production to tissue damage in frozen rhododendron leaf disks. J. Amer. Soc. Hort. Sci. 111:434-436.

Kimmerer, T.W. and T.T. Kozlowski. 1982. Ethylene, ethane, acetaldehyde, and ethanol production by plants under stress. Plant Physiol. 69:840-847.

Nanaiah, G.K. and J.A. Anderson. 1992. Electrolyte leakage and evolution of ethylene and ethane from pepper leaf disks following temperature stress and fatty acid infiltration. J. Amer. Soc. Hort. Sci. 117:846-851.

Pauls, K.P. and J.E. Thompson. 1980. In vitro simulation of senescence-related membrane damage by ozone-induced lipid peroxidation. Nature (London) 283:504-506.

Perkins, E.G. 1989. Gas chromatography and gas chromatography-mass spectrometry of odor/flavor components in lipid foods, p. 35-56. In: D.B Min and T.H. Smouse (eds.). Flavor chemistry of lipid foods. Amer. Oil Chem. Soc., Champaign, Ill.

Purvis, A.C. and R.L. Shewfelt. 1993. Does the alternative pathway ameliorate chilling injury in sensitive plant tissues? Physiol. Plant. 88:712-718.

\title{
Biological Roles and Biochemistry of the Lipoxygenase Pathway
}

\author{
Harold W. Gardner \\ National Center for Agricultural Utilization Research, Agricultural Research Service, U.S. Department of \\ Agriculture, Phytoproducts Research, 1815 North University Street, Peoria, IL 61604
}

Comparative overview of the plant and animal kingdoms. This workshop emphasized the "dark side" of uncontrolled lipid oxidation in plants, but another aspect of this oxidative process is thought to be a "normal" part of the physiological status of the plant and animal kingdoms. That is, the so-called lipoxygenase pathway is common to plants and animals (Fig. 1). Because the pathway in plants is activated by wounding and pathogen attack, the argument can be made that the pathway is normally quiescent. In animals, certain levels of prostaglandins and lipoxygenase products are known to be maintained, but only a few studies have addressed the endogenous levels of lipoxgenase metabolites in plants (e.g., see Vick and Zimmerman, 1982). More data are available concerning endogenous levels of the lipoxygenase pathway-generated jasmonic acid family of metabolites (see review in Hamberg and Gardner, 1992). Although some lipoxygenase isoenzymes can oxidize certain glyceride lipids, it is generally acknowledged that free polyunsaturated fatty acids are the preferred substrates. In plants, a little-known portion of the pathway is how the initial step is triggered, namely the lipolytic action on glycerides. Lipoxygenase oxidation of polyunsaturated fatty acids, and metabolism of the resulting fatty acid hydroperoxides, are more thoroughly characterized. However, the biosynthesis of prostaglandins via prostaglandin endoperoxide synthase has not yet been observed in plants. There are a few reports of prostaglandins isolated from plants, but few higher plants contain the arachidonic acid necessary for the action of prostaglandin endoperoxide synthase. Since prostaglandin-like fatty acids are formed simply by peroxidative reactions of hydroperoxides of either arachidonic acid or linolenic acid (O'Connor et al., 1984), it is unlikely that the "prostaglandins" found in plants resulted from true enzymic reactions of prostaglandin biosynthesis. Because higher plants largely metabolize their endogenous polyunsaturated fatty acids, linoleic and linolenic acids, and animals use mostly arachidonic acid in these reactions, they have been called the octadecanoid and eicosanoid pathways, respectively.

André and Hou first detected lipoxygenase in plants in 1932, but its significance was not understood until about 50 years later. Novel possible physiological roles for the lipoxygenase pathway in plants are now emerging rapidly. However, prostaglandin endoperoxide synthase

The cost of publishing this paper was defrayed in part by the payment of page charges. Under postal regulations, this paper therefore must be hereby marked advertisement solely to indicate this fact. and lipoxygenase activities in animals were discovered much later (Hamberg and Samuelsson, 1974; Nugteren et al., 1966), and their physiological roles were defined quickly thereafter. Although plants and animals diverged in their evolution more than 2.5 billion years ago, there remain several common enzymic reactions in the pathway in addition to lipoxygenase. Allene oxide synthase (formerly called hydroperoxide isomerase, hydroperoxide cyclase, and hydroperoxide dehydrase) is found in plants and coral (Fig. 1), and hydroperoxide lyase has been identified in plants and fish (see review in Gardner, 1991). Interestingly, both the octadecanoid and eicosanoid pathways are often triggered by stress. Many of the physiological responses are amelioration or repair of the effects of stress. For many years, aspirin has been known to block prostaglandin formation by inhibiting prostaglandin endoperoxide synthase activity. Recently, Peña-Cortés et al. (1993) reported that aspirin in plants also inhibits allene oxide synthase, the enzyme that produces the plant equivalent of prostaglandins (12oxo-phytodienoic acid).

An overview of the lipoxygenase or octadecanoid pathway of plants is shown in Fig. 2. After lipolytic action, the first enzyme in the series is lipoxygenase. Most plant lipoxygenase isoenzymes hydroperoxidize polyunsaturated fatty acids in a stereo-specific manner giving either $13(S)$ - or $9(S)$-hydroperoxides, and some yield a mixture of both. Only a few isoenzymes give a more racemic mixture, similar to fatty acid autoxidation products. Thus, the hydroperoxides usually obtained from linoleic acid are 13(S)-hydroperoxy-cis-9, trans11-octadecadienoic acid (13S-HPOD) and 9(S)-hydroperoxy-trans10, cis-12-octadecadienoic acid (9S-HPOD), and those obtained from linolenic acid are 13(S)-hydroperoxy-cis-9,trans-11,cis-15octadecatrienoic acid (13S-HPOT) and $9(S)$-hydroperoxy-trans-10, cis12,cis-15-octadecatrienoic acid (9S-HPOT). By Fischer convention the 13(S)- and $9(S)$-hydroperoxides are $(L)$ and $(D)$, respectively. After lipoxygenase action, there are several hydroperoxide-metabolizing branches of the pathway that impact the physiology of plants; these aspects are discussed in the sections below.

The jasmonic acid family. The key enzyme involved in the biosynthesis of the family of 7-iso-jasmonic acid, jasmonic acid, their esters, and numerous related metabolites was first observed in flaxseed (Linum usitatissimum L.) to transform 13S-HPOD into 12-oxo-13hydroxy-cis-9-octadecenoic acid ( $\alpha$-ketol).Zimmerman (1966) named this enzyme hydroperoxide isomerase. Subsequently, hydroperoxide isomerase was found in the germ of corn seed (Zea mays L.), and, 


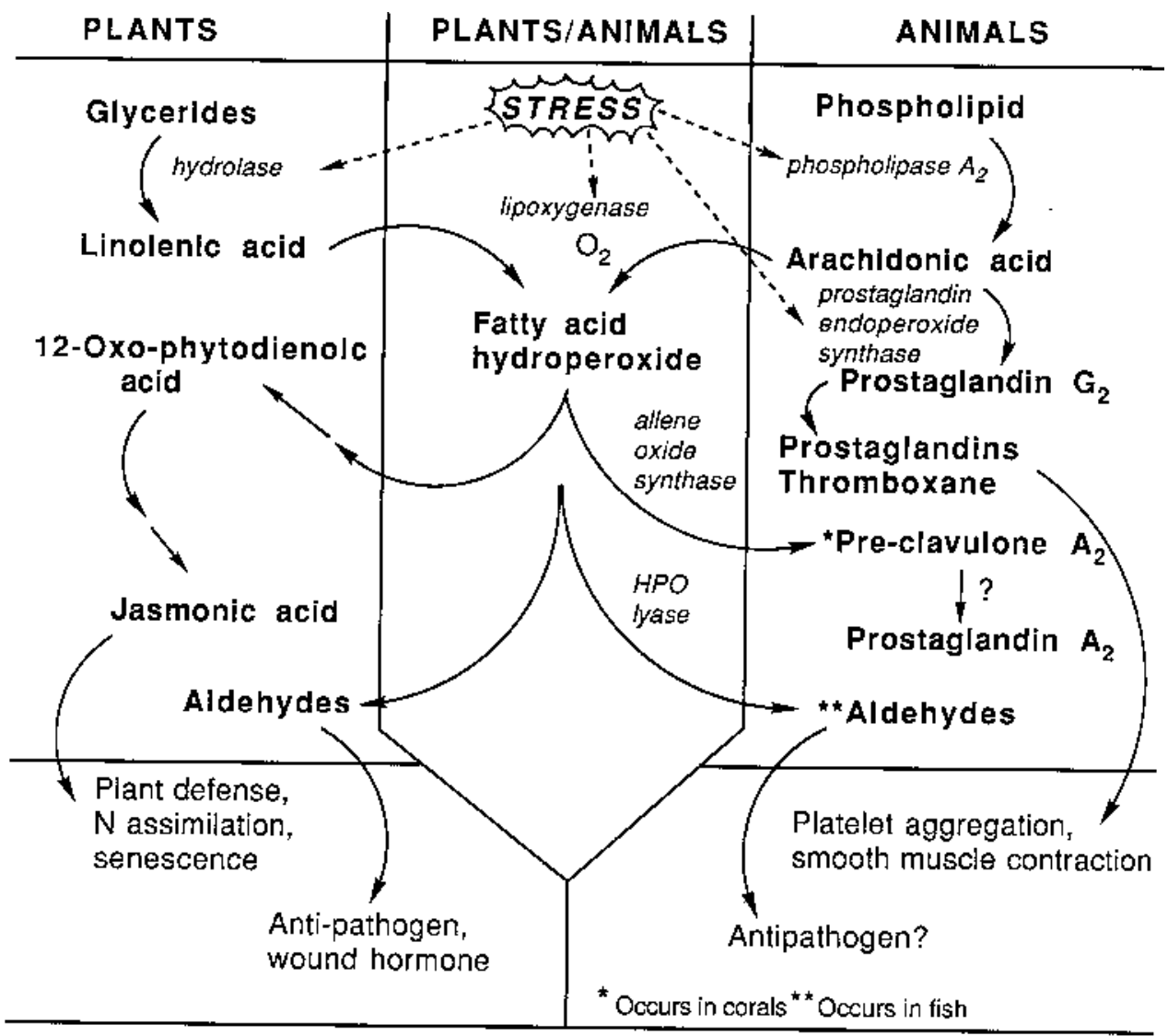

Fig. 1. Model of the stress-activated octadecanoid pathway of plants and eicosanoid pathway of animals showing reactions shared by both, as well as those unique to either the plant or animal kingdom.

\section{GLYCERIDE LIPIDS}

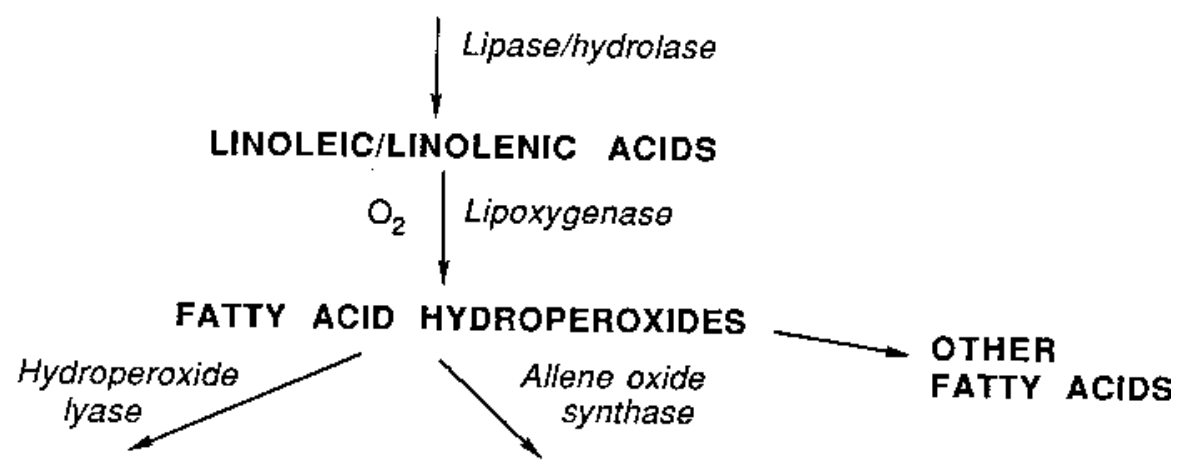

ALDEHYDES/

ALDEHYDE ACIDS

1

OTHER SHORT-

CHAIN METABOLITES

\section{ALLENE OXIDE FATTY ACIDS}

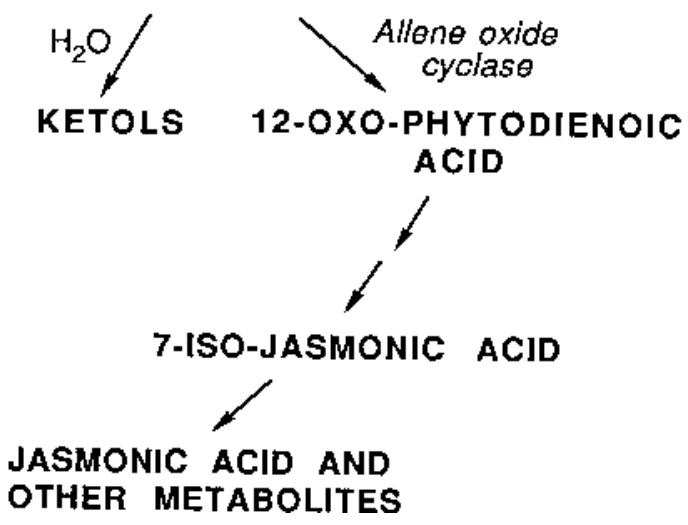

Fig. 2. A summary of the major metabolic branches in the plant octadecanoid pathway. 


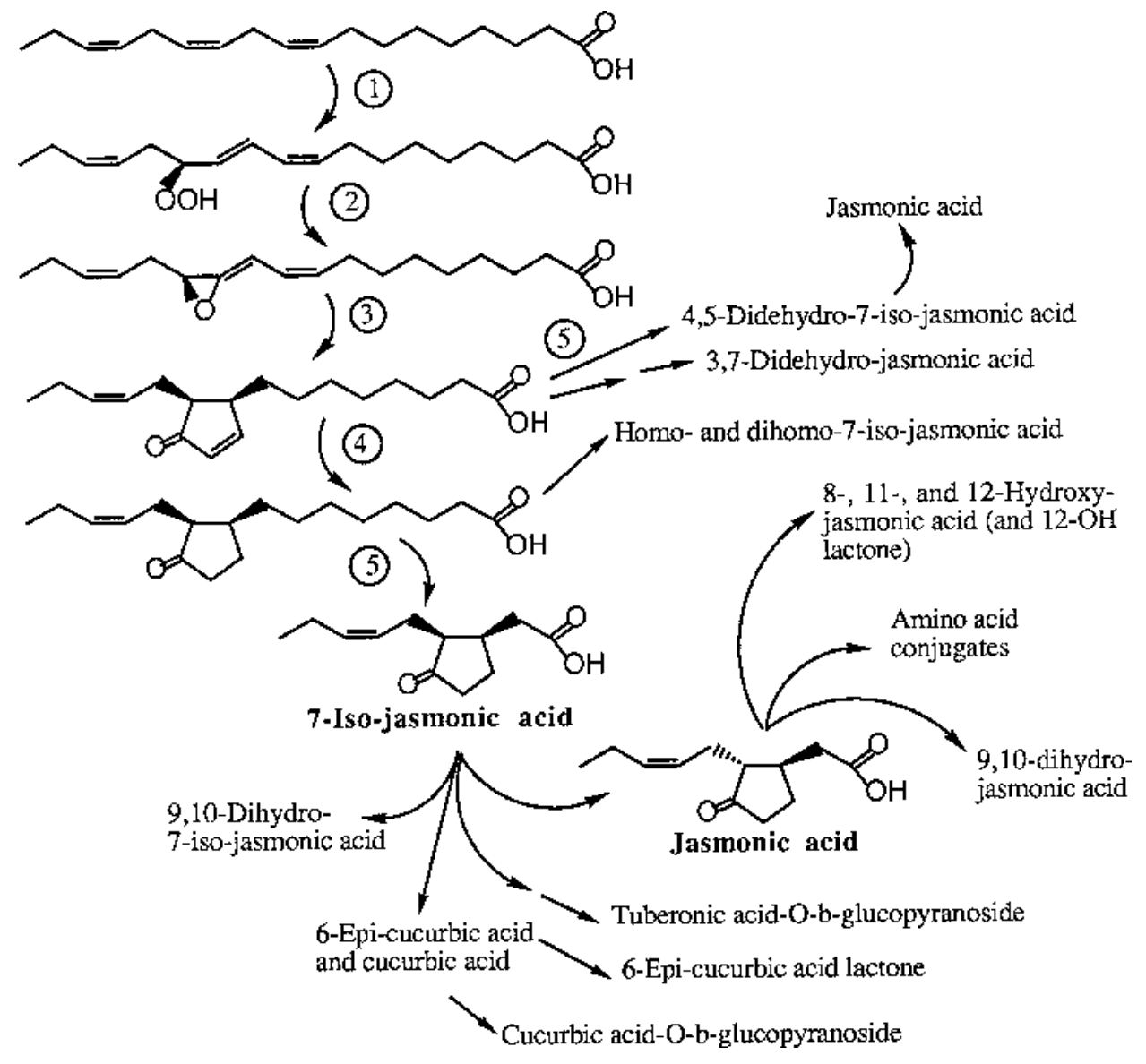

Fig. 3. The sequential conversion of linolenic acid into the jasmonic acid family of phytohormones. The enzymic reactions to 7-iso-jasmonic acid have been established as follows: 1) 13(S)-hydroperoxide-specific lipoxygenase, 2) allene oxide synthase, 3) allene oxide cyclase, 4) 12-oxo-phytodienoic acid reductase, 5 ) three $\beta$-oxidation steps. The other conversions shown have not been directly connected with specific enzymic reactions, but they are logical choices based on known biosynthetic reactions. Not shown are the esters of jasmonic and 7-iso-jasmonic acids; methyl and ethyl esters are known.

additionally, the $\gamma$-ketol, 12-oxo-9-hydroxy-trans-10-octadecenoic acid, was produced from $13 S$-HPOD (Gardner, 1970). The corn germ enzyme also converted 9S-HPOD into the corresponding $\alpha$ - and $\gamma$ ketols. Several years later, Zimmerman and Feng (1978) reported a "new" enzyme, hydroperoxide cyclase, that catalyzed the conversion of $13 S$-HPOT into a cyclic fatty acid, 12-oxo-phytodienoic acid. Subsequently, Hamberg (1987) showed that the $\alpha$ - and $\gamma$-ketols were derived from hydrolysis of the actual enzymic product, an unstable allene oxide fatty acid. He renamed the enzyme as hydroperoxide dehydrase, but this nomenclature was changed again to allene oxide synthase by Song and Brash (1991), who isolated the enzyme and characterized it as a cytochrome $\mathrm{P} 450$. The allene oxide synthase gene from flaxseed was recently cloned and sequenced (Song et al., 1993). Researchers soon recognized that the allene oxide fatty acid was the intermediate involved in cyclization of $13 \mathrm{~S}$-HPOT into 12-oxophytodienoic acid (Fig. 3) (Baertschi et al., 1988; Brash et al., 1988; Hamberg, 1988). Earlier, Corey et al. (1987) had suggested that an analogue of 12-oxo-phytodienoic acid, pre-clavulone A (Fig. 1), was formed in coral via a fatty acid allene oxide intermediate; a suggestion fully confirmed by Brash's group (Brash et al., 1987). In plants, only the $13 S$-HPOT was converted into the cyclic fatty acid; whereas allene oxides from the $9 S$-HPOT, $9 S$-HPOD, and $13 S$-HPOD exclusively underwent hydrolysis to the ketols. Reaction of $13 S$-HPOT catalyzed by allene oxide synthase results in the spontaneous cyclization of the intermediate allene oxide; however, hydrolysis to the ketols occurs to a larger extent. Also, spontaneous cyclization causes the formation of racemic 12-oxo-phytodienoic acid (9S, 13S, and 9R, 13R); but in the presence of another enzyme, allene oxide cyclase, mainly one isomer $(98 \%$ 9S, $13 \mathrm{~S})$ was found in increased yield at the expense of ketol formation (Hamberg and Fahlstadius, 1990).

The next steps in the pathway to jasmonic acid involved the reduction of the double bond of the cyclopentenone ring of 12-oxophytodienoic acid by a reductase (Vick and Zimmerman, 1986), followed by three successive $\beta$-oxidations (Vick and Zimmerman, 1983). As shown in Fig. 3, the immediate biosynthetic product is 7-isojasmonic acid, instead of jasmonic acid. Many derivatives related to jasmonic acid are known (see review in Hamberg and Gardner, 1992). Although the specific routes to these derivatives are unknown, the pathways shown in Fig. 3 were constructed by logical use of known biosynthetic reactions. The methyl ester of jasmonic acid, as well as 7iso-jasmonic acid, are commonly occurring natural derivatives. Investigators have used synthetic methyl jasmonate extensively as a "volatile signal" in physiological research.

The biological activities of the jasmonic acid family are extensive (see recent reviews in Farmer and Ryan, 1992a; Hamberg and Gardner, 1992; Sembdner and Parthier, 1993; Staswick, 1992; van den Berg and Ewing, 1991; Weiler, 1993). Because these reviews are available, the literature from 1992 to present will be emphasized, with only a brief summary given of the earlier research (Table 1). Physiological functions of the jasmonic acid family have been largely researched with a synthetic racemate of methyl jasmonate or jasmonic acid. According to Nishida et al. (1985), synthetic methyl jasmonate tends to be composed of $47.5 \%$ methyl jasmonate (natural), $47.5 \%$ methyl entjasmonate (unnatural), 2.5\% methyl 7-iso-jasmonate (natural), and $2.5 \%$ methyl ent-7-iso-jasmonate (unnatural); thus, it is reasonable to expect that the biological activity of the natural methyl esters may have a lower threshold than reported for synthetic racemates. As reported by Koda et al. (1992), methyl ent-7-iso-jasmonate and methyl entjasmonate had lower activity in some applications, but they equally inhibited the straight growth of oat (Avena sativa L.) coleoptiles, compared to the natural isomers. With some notable exceptions, such as the potato-tuberizing phytohormone, tuberonic acid- $O$ - $\beta$ - 
Table 1. Biological activities of methyl jasmonate, jasmonic acid, and related metabolites.

\begin{tabular}{|c|c|c|}
\hline Type of activity & Occurrence in plant and (tissue) ${ }^{2}$ & Investigators $^{y}$ \\
\hline \multicolumn{3}{|l|}{ Protein induction } \\
\hline Vegetative storage proteins & Soybean (leaves) & Anderson; Fransceschi \& Grimes; Staswick et al. \\
\hline Lipoxygenase & Soybean (leaves) & Bell \& Mullet; Tranbarger et al. \\
\hline Jasmonate-induced proteins & Barley (leaves, seedlings); 26 other species & Weidhase et al.; Mueller-Uri et al.; Hermann et al. \\
\hline Proteinase inhibitors & Tomato, tobacco, alfalfa (plants) & Farmer \& Ryan \\
\hline Napin & Rape (embryo culture) & Wilen et al. \\
\hline Cruciferin & Rape (embryo culture) & Wilen et al. \\
\hline Oil-body proteins & Rape, flaxseed (embryo culture) & Wilen et al. \\
\hline Phenylalanine lyase & Soybean (cell culture) & Gundlach et al. \\
\hline Polyphenol oxidase & Apples (fruit), tulip (bulbs) & Czapski et al.; Saniewski \& Czapski \\
\hline Peroxidase & Barley (leaves), tulip (bulbs) & Weidhase et al.; Saniewski \& Czapski \\
\hline \multicolumn{3}{|l|}{ Protein degradation } \\
\hline Rubisco & Barley (leaves) & Weidhase et al.; Popova \& Vaklinova; Maslenkova et al \\
\hline \multicolumn{3}{|l|}{ Secondary metabolite induction } \\
\hline Flavonoids, alkaloids, others & Eschscholtzia, others (cell culture) & Gundlach et al. \\
\hline Anthocyanin & Soybean (seedlings) & Franceschi \& Grimes \\
\hline Tuberization induction & Potato (tubers) & Koda et al.; Yoshihara et al. \\
\hline \multicolumn{3}{|l|}{ Senescence and growth inhibition } \\
\hline Growth inhibition & Rice, wheat, oat, other (seedling) & Yamane et al.; Miersch et al.; Dathe et al.; others \\
\hline Increased respiration & Barley (seedling) & Popova et al.; Satler \& Thimann \\
\hline Leaf abscission & Ficus superba Miq. (leaves) & Ueda et al. \\
\hline Increased stomatal resistance & Commelina benghalensis L., other (leaves) & Raghavendra \& Reddy; Satler \& Thimann \\
\hline Chlorophyll loss & Barley, oat, other (leaves) & Ueda \& Kato; Miersch et al.; Ueda et al.; others \\
\hline \multicolumn{3}{|l|}{ Other effects } \\
\hline Ethylene stimulation & Tomato, apple (fruit) & Saniewski et al.; Czapski \& Saniewski \\
\hline Germination inhibition & Oat, wheat, other (seed), camellia (pollen) & Corbineau et al.; Yamane et al.; Wilen et al.; others \\
\hline Germination stimulation & Seeds requiring cold stratification & Daletskaya \& Sembdner; Berestetzky et al. \\
\hline Tendril coiling & Bryonia dioica Jacq. (tendrils) & Falkenstein et al. \\
\hline Leaf opening inhibition & Mimosa pudica L. (leaves) & Tsurumi \& Asahi \\
\hline Volatile ester inhibition & Apple (fruit) & Olías et al. \\
\hline Lycopene inhibition & Tomato (fruit) & Saniewski \& Czapski \\
\hline
\end{tabular}

${ }^{2}$ Tobacco, Nicotiana tabacum L.; alfalfa, Medicago sativa L.; rape, Brassica napus L.; apple, Malus sp. and Malus malus cv. Golden Delicious; tulip, Tulipa sp.; Eschscholtzia, Eschscholtzia californica Cham.; wheat, Triticum aestivum L.; camellia, Camellia sinensis L.

${ }^{\mathrm{y}}$ References are not available in Literature Cited. See Hamberg and Gardner (1992) for full citations.

glucopyranoside (Yoshihara et al., 1989), little is known of the biological activity of the various other metabolites of jasmonic acid and 7-iso-jasmonic acid. Another unknown is the fate or function of allene oxide hydrolysis products, the $\alpha$ - and $\gamma$-ketols.

Recent investigations have increasingly indicated that predation by herbivores (wounding), elicitation by fungi (hypersensitive response), or both are signaled by the lipoxygenase pathway, and the defense response to the signal occurs at the transcriptional level. This signal is theorized to be the jasmonic acid (or 7-iso-jasmonic acid) produced via the octadecanoid pathway. A reasonable model has been outlined by Farmer and Ryan (1992a, 1992b), which suggests that either a pathogen or a herbivore signals a receptor in the plasma membrane. According to the model, the receptors cause activation of lipase, and this in turn initiates the octadecanoid pathway to jasmonic acid and gene activation. Thus far, there is limited evidence for the activation of lipase by elicitation. Lipoxygenase's role in the hypersensitive response was demonstrated by a negative elicitor response using a lipoxygenase-null potato (Solanum tuberosum L.) callus culture, compared with a lipoxygenase-positive culture (Vaughn and Lulai, 1992). Mueller et al. (1993) found that adding fungal cell walls to a variety of plant cell cultures resulted in the release of free linolenic acid, and within $1 \mathrm{~h}$, the transient formation of 7-iso-jasmonic acid, as well as 12-oxo-phytodienoic acid. In turn, jasmonic/7-iso-jasmonic acid produced as a result of elicitation induces mRNAs for the production of defensive proteins (Dittrich et al., 1992; Gundlach et al., 1992). These proteins, such as phenylalanine ammonia lyase, 4-coumarate:CoA ligase, and chalcone synthase, stimulated production of defensive secondary metabolites. Other recently reported defensive proteins induced by either jasmonic acid, methyl jasmonate, or their precursors (e.g., 12-oxo-phytodienoic acid) include a Kunitz-type proteinase inhibitor (Yamagishi et al., 1993), tobacco proteinase inhibitor (Rickauer et al., 1992), potato proteinase inhibitor II (Kim et al., 1992; Peña-Cortés et al., 1992), a precursor of leaf thionin (Andresen et al., 1992), and several proteinase inhibitors (Farmer and Ryan, 1992b; Farmer et al., 1992). However, it has been recently questioned if the proteinase inhibitors or other proteins play an important role in protection against fungal attack. According to some workers (Cohen et al., 1993; Schweizer et al., 1993), other factors may be important. It has been amply demonstrated that lipoxygenase activity is induced by either wounding or fungal elicitors (e.g., Croft et al., 1990; Fournier et al., 1993; Hildebrand et al., 1989; Melan et al., 1993). Possibly, increased levels of certain lipoxygenase isozymes are a result of methyl jasmonate (or jasmonic acid) induction, such as observed for a lipoxygenase in soybean (Glycine max L.) (Grimes et al., 1992). The increased expression of lipoxygenase could function simply as a vegetative storage protein (Grimes et al., 1992) or could amplify the signal after pathogen attack.

Similar to induction by elicitors, wounding causes expression of a variety of proteins in a manner similar to the induction of these proteins by either methyl jasmonate, jasmonic acid, or their precursors (Farmer and Ryan, 1992b; Farmer et al., 1992; Hildmann et al., 1992). Wounding caused the transient formation of 7-iso-jasmonic acid, which peaked within 30 min to $2 \mathrm{~h}$ (Albrecht et al., 1993). Creelman et al. (1992) also observed jasmonic acid and methyl jasmonate accumulation after wounding soybean stems. Stimulation of Bryonia dioica Jacq. tendrils by streaking with a wooden stick was sufficient to increase the level of jasmonic acid (Weiler et al., 1993). Although wounding causes transient production of the jasmonic acid family of compounds and they induce proteins at the transcriptional level, surprisingly, gene deletion analysis showed that the induction mechanism of potato proteinase inhibitor II by wounding is different from induction by methyl jasmonate (Kim et al., 1992).

In addition, proteins that have no obvious plant defense function are expressed in the presence of either methyl jasmonate or jasmonic acid. Some serve as vegetative storage proteins, like those found earlier in soybean (Glycine max L.) leaves. Soybean storage proteins act as $\mathrm{N}$ sinks within the leaf before their mobilization during seed development. Recent reports include determination of the sequence of the jasmonate-inducible 23-kD (Andresen et al., 1992) and 60-kD (Becker and Apel, 1992) proteins of barley (Hordeum vulgare L.) and detection of an inducible vegetative storage protein in Arabidopsis thaliana L. (Staswick et al., 1992). In contrast, methyl jasmonate 
caused the decline of certain photosynthetic enzymes. Methyl jasmonate impaired translation of transcripts for the large and small subunits of rubisco as well as several light-harvesting chlorophyll-protein complex apoproteins (Reinbothe et al., 1993a, 1993b). It is tempting to hypothesize that plants use the jasmonic acid phytohormones as a signal to switch normal photosynthetic function of the plant to a defensive mode through $\mathrm{N}$ storage and production of defensive substances. Possibly, they also may control $\mathrm{N}$ assimilate partitioning between vegetative and reproductive tissue.

Other biological effects of methyl jasmonate/jasmonic acid studied recently include ethylene biosynthesis (Chou and Kao, 1992a; Sanz et al., 1993), potato (Solanum tuberosum L.) tuberization (Matsuki et al., 1992), tendril coiling (Weiler et al., 1993), seed germination (Ranjan and Lewak, 1992), leaf senescence (Chou and Kao, 1992b), and onion (Allium cepa L.) bulbing (Nojiri et al., 1992). Gene expression induced by methyl jasmonate has been compared with similar promoters, such as abscisic acid, desiccation, wounding, and sucrose (Lorbeth et al., 1992; Mason et al., 1992; Reinbothe et al., 1992).

The aldehyde pathway. Hydroperoxide lyase is an enzyme that cleaves fatty acid hydroperoxides into two fragments at the position between the hydroperoxide-bearing carbon and the double bond. This cleavage results in aldehydic functions on both sides of the site of cleavage, producing both an alkanal/alkenal and an oxo-acid. Generally, there are hydroperoxide lyases specific for either 9-hydroperoxides of linoleic/linolenic acids or 13-hydroperoxides of linoleic/linolenic acids. Although various hydroperoxide lyase enzymes have not been investigated completely in regard to their stereo-selectivity for hydroperoxide substrates, a few have been identified as being specific for hydroperoxides with the $S$-configuration, but thus far, none has been identified as $R$-specific. Recent reviews outline these pathways in more detail (Gardner, 1989, 1991; Hatanaka et al., 1987).

Hydroperoxide-lyase-catalyzed reactions are commonly observed in plants, particularly in wounded tissues, and they often result in characteristic plant odors. 13-Hydroperoxides of linoleic and linolenic acid cleave into hexanal and cis-3-hexenal, respectively, as well as 12oxo-cis-9-dodecenoic acid (Fig. 4). A hydroperoxide lyase specific for 13-hydroperoxides was recently isolated from tea [Camellia sinensis
(L.) Ktze.] leaves (Matsui et al., 1991). The cis-3-hexenal and 12-oxocis-9-dodecenoic acid are often isomerized by an alkenal isomerase (Phillips et al., 1979) into trans-2-hexenal and 12-oxo-trans-10dodecenoic acid, respectively. Zimmerman and Coudron (1979) showed that the latter oxo-acid is a wound hormone, "traumatin," and this compound is undoubtedly the precursor of "traumatic acid," which English et al. described in 1939. Hexanal has a rancid green odor, whereas cis-3-hexenal and trans-2-hexenal have intense grassy and spicy-green odors, respectively. Alcohol dehydrogenases reduce the aldehydes into the corresponding alcohols (Fig. 4) (Matoba et al., 1989), which lead to similar, more subdued odors. Recently, the pathway has been expanded to include the conversion of cis-3-hexenal into 4-hydroxy-trans-2-hexenal (Gardner and Hamberg, 1993). 4Hydroxy-trans-2-hexenal, as well as the more intensively studied 4hydroxy-trans-2-nonenal, are genotoxic and cytotoxic (reviewed by Esterbauer et al., 1991).

Cleavage of 9-hydroperoxides proceeds by the process described above, except the products are either cis-3-nonenal or cis-3,cis-6nonadienal from the hydroperoxides of linoleic or linolenic acids, respectively, as well as 9-oxononanoic acid (Fig. 5). The 9-hydroperoxide-specific hydroperoxide lyase has been separated from the 13hydroperoxide-specific lyase, indicating that they are individual isoenzymes (Matsui et al., 1989). After formation of the C-9 aldehydes, other transformations occur similar to those discussed above for the aldehydes derived from 13-hydroperoxides (Fig. 5). The odors produced by cleavage of 9-hydroperoxides are principally due to the intense cucumber (Cucumis sativus L.)-like odor of cis-3-nonenal and cis-3,cis-6-nonadienal with a more subdued and altered odor contributed by their corresponding alcohols or trans-2-alkenals.

Another type of hydroperoxide lyase, affording different cleavage fragments from those discussed above, has been reported in fungi, alga, and a species of grass. For example, this hydroperoxide lyase converts $13 S$-HPOD into either pentanol or pentane, as well as 13-oxotrans-11,cis-9-octadecadienoic acid (see review in Gardner, 1991). A particularly interesting reaction of this type is found in mushroom (Psalliota bispora Lange). Apparently, a lipoxygenase may exist that is specific for oxidizing the $10 \mathrm{~S}$-position of fatty acid; that is, mush-

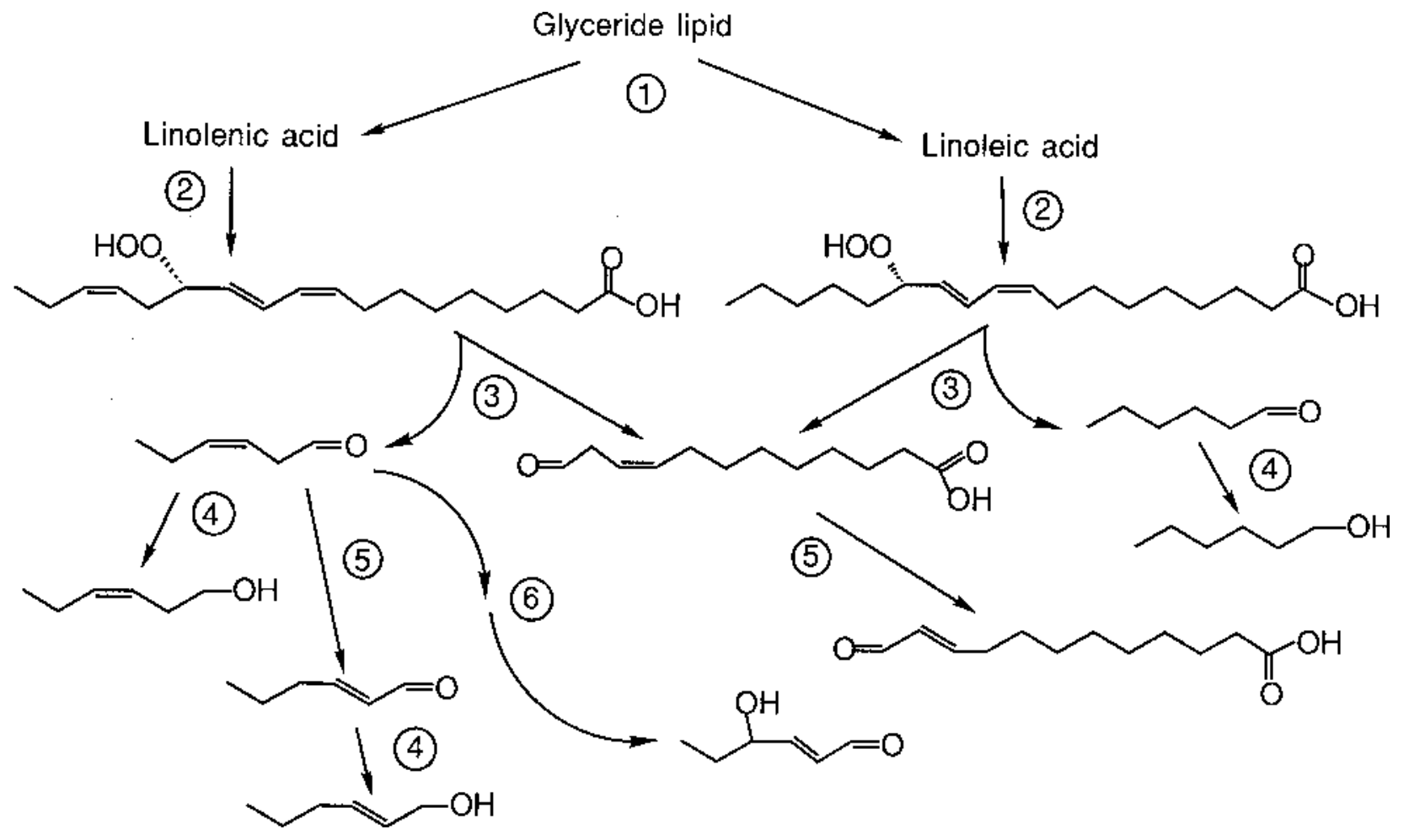

Fig. 4. The $\mathrm{C}_{6}-\mathrm{C}_{12}$ cleavage pathway to aldehydes and alcohols via a 13(S)-hydroperoxide-specific lipoxygenase. The specific enzymes involved are 1) a family of lipolytic enzymes, 2) 13(S)-hydroperoxide-specific lipoxygenase, 3) hydroperoxide lyase, 4) alcohol dehydrogenase, 5) cis-3(9):trans-2(10)-enal isomerase, 6) cis-3-alkenal oxygenase and hydroperoxide epoxygenase. 


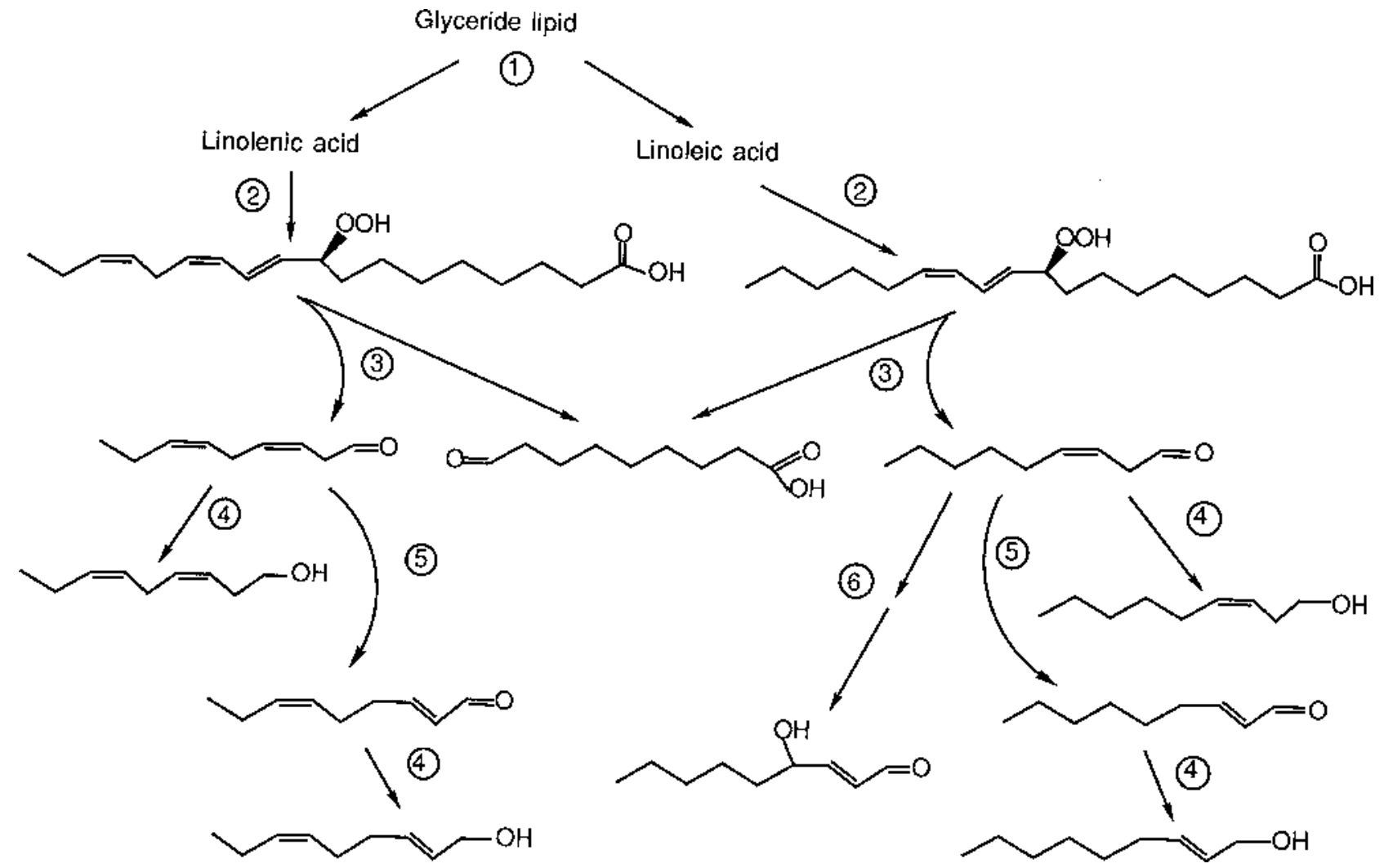

Fig. 5. The $\mathrm{C}_{9}-\mathrm{C}_{9}$ cleavage pathway to aldehydes via a $9(S)$-hydroperoxide-specific lipoxygenase. The specific enzymes are 1) a family of lipolytic enzymes, 2 ) $9(S)$-hydroperoxide-specific lipoxygenase, 3) hydroperoxide lyase, 4) alcohol dehydrogenase, 5) cis-3:trans-2-enal isomerase, 6) cis-3-alkenal oxygenase and hydroperoxide epoxygenase.

room hydroperoxide lyase cleaved the $10 S$-hydroperoxide of linoleic acid into 1-octen-3-ol and 10-oxo-trans-8-decenoic acid(Wurzenberger and Grosch, 1984). 1-Octen-3-ol is an important flavor component of mushrooms.

A role for the aldehydes languished in obscurity for many years after the first reports of physiological activity. Major et al. (1960) and Schildknecht and Rauch (1961) found that trans-2-hexenal was fungitoxic, and Nandi and Fries (1976) found antifungal activity with other hydroperoxide-lyase-derived aldehydes. Subsequently, Zimmerman and Coudron (1979) reported a wound-healing action of 12-oxo-trans-10-dodecenoic acid. More recently, there have been numerous investigations of antifungal and antimicrobial activity of the hydroperoxide-lyase-generated aldehydes, including activity against certain pathogenic strains of these organisms (Bradow, 1991; Croft et al., 1993; Deng et al., 1993; Doehlert et al., 1993; Gardner et al., 1990; Gueldner et al., 1985; Hamilton-Kemp et al., 1992; Urbasch, 1987; Vaughn and Gardner, 1993; Zeringue and McCormick, 1989, 1990). In one particularly interesting study (Croft et al., 1993), Phaseolus vulgaris L. leaves inoculated with an avirulent strain of Pseudomonas syringae pv phaseolicola Burkholder caused a burst of hexenals and hexenols after 15 to $24 \mathrm{~h}$, which corresponds to the time of the hypersensitive response. One of the hexenals, trans-2-hexenal, was particularly inhibitory to the growth of $P$. syringae pv phaseolicola. Because the hexenal/hexenol burst occurred before phytoalexin accumulation, these compounds may be early volatile phytoalexins important to early plant responses. However, a virulent, compatible strain of $P$. syringae pv phaseolicola elicited hexenals/hexenols only at levels slightly above the controls. In addition to antifungal and antimicrobial activity, anti-insect activity has been demonstrated for some of the aldehydes (Chamberlain et al., 1991; Hildebrand et al., personal communication; Mohri et al., 1990).

The fungitoxicity of 4-hydroxy-trans-2-nonenal is comparatively high (Vaughn and Gardner, 1993). In addition to antifungal activity, the 4-hydroxy-alkenals, including 4-hydroxy-trans-2-hexenal, may cause other physiological effects. According to Esterbauer (1992), 4hydroxy-trans-2-nonenal may modulate gene expression. Since 4- hydroxy-trans-2-nonenal and 4-hydroxy-trans-2-hexenal activate phospholipase D, these 4-hydroxy-alkenals also appear to have some control over the generation of second messengers, such as phoshatidic acid and diacylglycerol (Natarajan et al., 1993). At least one enzyme, glucose-6-phosphate dehydrogenase, has been inactivated by exposure to 4-hydroxy-trans-2-nonenal (Szweda et al., 1993).

Other hydroperoxide-decomposing enzymes. Another major pathway of linoleic/linolenic acid hydroperoxide metabolism involves the formation of hydroxy-diene/triene, epoxy-ene/diene, epoxyhydroxyene/diene, and trihydroxy-ene/diene fatty acids. There has been some debate about the relative importance of two possible pathways of formation of these fatty acids. As ascertained in the laboratories of Blée (Blée and Schuber, 1990a, 1990b; Blée et al., 1993) and Hamberg (Hamberg and Fahlstadius, 1992; Hamberg and Hamberg, 1990), one pathway, catalyzed by hydroperoxide-dependent peroxygenase (or epoxygenase), involves the epoxidation of double bonds with peroxide oxygen, resulting in the simultaneous reduction of hydroperoxide to hydroxide. Primary products are epoxy-, epoxyhydroxy-ene/diene, and hydroxy-diene/triene fatty acids. Trihydroxy-ene/diene fatty acids are hydrolysis products of epoxyhydroxy-ene/diene fatty acids. An alternative pathway involves formation of an alkoxyl radical from hydroperoxide and subsequent alkoxyl rearrangement into epoxyhydroxy-ene/diene fatty acids (for a discussion of these two possibilities, see review by Gardner, 1991).

The physiological importance of the various oxygenated fatty acids discussed in the preceding paragraph has been attributed to their antifungal action against rice blast disease (Kato et al., 1983, 1984, 1985, 1986a, 1986b, 1991; Ohta et al., 1990; Shimura et al., 1983). Both lipoxygenase and lipid hydroperoxide-decomposing activities are activated after infection of rice (Oryza sativa L.) with rice blast fungus, especially with an incompatible strain of the fungus (Ohta et al., 1991). In addition, two products of the lipoxygenase and lipid hydroperoxide-decomposing system elicited phytoalexins in Oryza sativa $\mathrm{L}$. (Li et al., 1991). Similarly, a trihydroxy-ene fatty acid is produced by the root of Colocasia esculenta var. antiquorum L. in defense against Ceratocystis fimbriata, the black rot fungus (Masui 
and Kojima, 1990; Masui et al., 1989). And, according to Blée and Schuber (1993), the various fatty acids produced by the hydroperoxide-dependent peroxygenase reaction are cutin monomers and their precursors. The production of a cutin barrier may be yet another important defensive function of the lipoxygenase pathway in plants.

\section{Literature Cited}

Albrecht, T., et al. 1993. Quantification of rapid, transient increases in jasmonic acid in wounded plants using a monoclonal antibody. Planta 191:86-94.

André, É. and K. Hou. 1932. The presence of a lipoid oxidase in soy bean, Glycine soja, Lieb. C.R. Acad. Sci. Paris 194:645-647 (Chem. Abstr. 1932. 26:3004.)

Andresen, I., et al. 1992. The identification of leaf thionin as one of the main jasmonate-induced proteins of barley (Hordeum vulgare). Plant Mol. Biol. 19:193-204.

Baertschi, S.W., C.D. Ingram, T.M. Harris, and A.R. Brash. 1988. Absolute configuration of cis-12-oxophytodienoic acid of flaxseed: Implications for the mechanism of biosynthesis from the 13(S)-hydroperoxide of linolenic acid. Biochemistry 27:18-24.

Becker, W. and K. Apel. 1992. Isolation and characterization of a cDNA clone encoding a novel jasmonate-induced protein of barley (Hordeum vulgare L.). Plant Mol. Biol. 19:1065-1067.

Blée, E. and F. Schuber. 1990a. Stereochemistry of the epoxidation of fatty acids catalyzed by soybean peroxygenase. Biochem. Biophys. Res. Commun. 173:1354-1360.

Blée, E. and F. Schuber. 1990b. Efficient epoxidation of unsaturated fatty acids by a hydroperoxide-dependent oxygenase. J. Biol. Chem. 265:1288712894.

Blée, E. and F. Schuber. 1993. Biosynthesis of cutin monomers: Involvement of a lipoxygenase/peroxygenase pathway. Plant J. 4:113-123.

Blée, E., A.L. Wilcox, L.J. Marnett, and F. Schuber. 1993. Mechanism of reaction of fatty acid hydroperoxides with soybean peroxygenase. J. Biol. Chem. 268:1708-1715.

Bradow, J.M. 1991. Relationship between chemical structure and inhibitory activity of $\mathrm{C}_{6}$ through $\mathrm{C}_{9}$ volatiles emitted by plant residues. J. Chem. Ecol. 17:2193-2212.

Brash, A.R., S.W. Baertschi, C.D. Ingram, and T.M. Harris. 1987. On noncyclooxygenase prostaglandin synthesis in the sea whip coral, Plexaura homomalla: An 8(R)-lipoxygenase pathway leads to formation of an $\alpha$ ketol and a racemic prostanoid. J. Biol. Chem. 262:15829-15839.

Brash, A.R., S.W. Baertschi, C.D. Ingram, and T.M. Harris. 1988. Isolation and characterization of natural allene oxides: Unstable intermediates in the metabolism of lipid hydroperoxides. Proc. Natl. Acad. Sci. USA 85:33823386.

Chamberlain, D.A., G. Wilson, and M.F. Ryan. 1991. trans-2-Nonenal insect repellent, insecticide, and flavor compound in carrot roots, cell suspensions, and "hairy" root cultures. J. Chem. Ecol. 17:615-624.

Chou, M.C. and C.H. Kao. 1992a. Stimulation of 1-aminocyclopropane-1carboxylic acid-dependent ethylene production in detached rice leaves by methyl jasmonate. Plant Sci. 83:137-141.

Chou, M.C. and C.H. Kao. 1992b. Methyl jasmonate, calcium, and leaf senescence in rice. Plant Physiol. 99:1693-1694.

Cohen, Y., U. Gisi, and T. Niderman. 1993. Local and systemic protection against Phytophthora infestans induced in potato and tomato plant by jasmonic acid and jasmonic methyl ester. Phytopathology 83:1054-1062.

Corey, E.J., M. d'Alarcao, S.P.T. Matsuda, and P.T. Lansbury, Jr. 1987. Intermediacy of 8-( $R)$-HPETE in the conversion of arachidonic acid to preclavulone A by Clavularia viridis. Implications for the biosynthesis of marine prostanoids. J. Amer. Chem. Soc. 109:289-290.

Creelman, R.A., M.L. Tierney, and J.E. Mullet. 1992. Jasmonic acid/methyl jasmonate accumulate in wounded soybean hypocotyls and modulate wound gene expression. Proc. Natl. Acad. Sci. USA 89:4938-4941.

Croft, K.P.C., F. Jüttner, and A.J. Slusarenko. 1993. Volatile products of the lipoxygenase pathway evolved from Phaseolus vulgaris (L.) leaves inoculated with Pseudomonas syringae pv phaseolicola. Plant Physiol. 101:1324.

Croft, K.P.C., C.R. Voisey, and A.J. Slusarenko. 1990. Mechanism of hypersensitive cell collapse: Correlation of increased lipoxygenase activity with membrane damage in leaves of Phaseolus vulgaris (L.) inoculated with an avirulent race of Pseudomonas syringae pv. phaseolicola. Physiol. Mol. Plant Pathol. 36:49-62.

Deng, W., et al. 1993. Effects of six-carbon aldehydes and alcohols on bacterial proliferation. J. Agr. Food Chem. 41:506-510.

Dittrich, H., T.M. Kutchan, and M.H.Zenk. 1992. The jasmonate precursor, 12oxo-phytodienoic acid, induces phytoalexin synthesis in Petroselinum crispum cell cultures. FEBS Lett. 309:33-36.

Doehlert, D.C., D.T. Wicklow, and H.W. Gardner. 1993. Evidence implicating the lipoxygenase pathway for providing resistance to soybeans against Aspergillus flavus. Phytopathology 83:1473-1477.

English, J. Jr., J. Bonner, and A.J. Haagen-Smit. 1939. Structure and synthesis of a plant wound hormone. Science 90:329.

Esterbauer, H. 1992. Biochemical aspects. Soc. Free Radical Res. Nwsl. 2(2):5.

Esterbauer, H., R.J. Schaur, and H. Zollner. 1991. Chemistry and biochemistry of 4-hydroxynonenal, malonaldehyde and related aldehydes. Free Radical Biol. Med. 11:81-128.

Farmer, E.E., R.R. Johnson, and C.A. Ryan. 1992. Regulation of expression of proteinase inhibitor genes by methyl jasmonate and jasmonic acid. Plant Physiol. 98:995-1002.

Farmer, E.E. and C.A. Ryan. 1992a. Octadecanoid-derived signals in plants. Trends Cell Biol. 2:236-240.

Farmer, E.E. and C.A. Ryan. 1992b. Octadecanoid precursors of jasmonic acid activate the synthesis of wound-inducible proteinase inhibitors. Plant Cell 4:129-134

Fournier, J., et al. 1993. Purification and characterization of elicitor-induced lipoxygenase in tobacco cells. Plant J. 3:63-70.

Gardner, H.W. 1970. Sequential enzymes of linoleic acid oxidation in corn germ: Lipoxygenase and linoleate hydroperoxide isomerase. J. Lipid Res. 11:311-321.

Gardner, H.W. 1989. How the lipoxygenase pathway affects the organoleptic properties of fresh fruit and vegetables, p. 98-112. In: D.B. Min and T.H. Smouse (eds.). Flavor chemistry of lipid foods. Amer. Oil Chem. Soc., Champaign, Ill.

Gardner, H.W. 1991. Recent investigations into the lipoxygenase pathway of plants. Biochim. Biophys. Acta 1084:221-239.

Gardner, H.W., D.L. Dornbos, Jr., and A.E. Desjardins. 1990. Hexanal, trans2-hexenal, and trans-2-nonenal inhibit soybean, Glycine max, seed germination. J. Agr. Food Chem. 38:1316-1320.

Gardner, H.W. and M. Hamberg. 1993. Oxygenation of 3(Z)-nonenal to (2E)4-hydroxy-2-nonenal in the broad bean (Vicia faba L.). J. Biol. Chem. 268:6971-6977.

Grimes, H.D., D.S. Koetje, and V.R. Franceschi. 1992. Expression, activity, and cellular accumulation of methyl jasmonate-responsive lipoxygenase in soybean seedlings. Plant Physiol. 100:433-443.

Gueldner, R.C., D.M. Wilson, and A.R. Heidt. 1985. Volatile compounds inhibiting Aspergillus flavus. J. Agr. Food Chem. 33:411-413.

Gundlach, H., M.J. Müller, T.M. Kutchan, and M.H.Zenk. 1992. Jasmonic acid is a signal transducer in elicitor-induced plant cell cultures. Proc. Natl. Acad. Sci. USA 89:2389-2393.

Hamberg, M. 1987. Mechanism of corn hydroperoxide isomerase: Detection of 12,13(S)-oxido-9(Z),11-octadecadienoic acid. Biochim. Biophys. Acta 920:76-84

Hamberg, M. 1988. Biosynthesis of 12-oxo-10,15(Z)-phytodienoic acid: Identification of an allene oxide cyclase. Biochem. Biophys. Res. Commun. 156:543-550.

Hamberg, M. and P. Fahlstadius. 1990. Allene oxide cyclase: A new enzyme in plant lipid metabolism. Arch. Biochem. Biophys. 276:518-526.

Hamberg, M. and P. Fahlstadius. 1992. On the specificity of a fatty acid epoxygenase in broad bean (Vicia faba L.). Plant Physiol. 99:987-995.

Hamberg, M. and H.W. Gardner. 1992. Oxylipin pathway to jasmonates: Biochemistry and biological significance. Biochim. Biophys. Acta 1165:118.

Hamberg, M. and G. Hamberg. 1990. Hydroperoxide-dependent epoxidation of unsaturated fatty acids in the broad bean (Vicia faba L.). Arch. Biochem. Biophys. 283:409-416

Hamberg, M. and B. Samuelsson. 1974. Prostaglandin endoperoxides. Novel transformations of arachidonic acid in human platelets. Proc. Natl. Acad. Sci. USA 71:3400-3404.

Hamilton-Kemp, T.R., C.T. McCracken, Jr., J.H. Loughrin, R.A. Andersen, and D.F. Hildebrand. 1992. Effects of some natural volatile compounds on the pathogenic fungi Alternaria alternata and Botrytis cinerea. J. Chem. Ecol. 18:1083-1091.

Hatanaka, A., T. Kajiwara, and J. Sekiya. 1987. Biosynthetic pathway for $\mathrm{C}_{6}$ aldehydes formation from linolenic acid in green leaves. Chem. Phys. Lipids 44:341-361.

Hildebrand, D.F., J.G. Rodriguez, C.S. Legg, G.C. Brown, and G. Bookjans. 1989. The effects of wounding and mite infestation on soybean leaf lipoxygenase levels. Z. Naturforsch. 44c:655-659.

Hildmann, T., et al. 1992. General roles of abscisic and jasmonic acids in gene activation as a result of mechanical wounding. Plant Cell 4:1157-1170.

Kato, T., et al. 1983. Self defensive substances in rice plant against rice blast disease. Tetrahedron Lett. 24:4715-4718.

Kato, T., et al. 1984. Unsaturated hydroxy fatty acids, the self defensive substances in rice plant against rice blast disease. Chem. Lett. p. 409-412.

Kato, T., et al. 1985. Structure and synthesis of unsaturated trihydroxy $\mathrm{C}_{18}$ fatty acids in rice plant suffering from rice blast disease. Tetrahedron Lett. 26:2357-2360. 
Kato, T., et al. 1986a. Structural elucidation of 11-hydroxy-12,13epoxyoctadeca- $(9 Z, 15 Z)$-dienoic acids from rice plants suffering from rice blast disease. J. Chem. Soc. Chem. Commun. p. 743-744.

Kato, T., et al. 1986b. Structure and synthesis of 11,12,13-trihydroxy-9Z,15Zoctadecadienoic acids from rice plant suffering from rice blast disease. Chem. Lett. p. 577-580.

Kato, T., Y. Yamaguchi, T. Hirukawa, and N. Hoshino. 1991. Structural elucidation of naturally occurring 9,12,13-trihydroxy fatty acids by a synthetic study. Agr. Biol. Chem. 55:1349-1357.

Kim, S.-R., J.-L. Choi, M.A. Costa, and G. An. 1992. Identification of G-box sequence as an essential element for methyl jasmonate response of potato proteinase inhibitor II promoter. Plant Physiol. 99:627-631.

Koda, Y., Y. Kikuta, T. Kitahara, T. Nishi, and K. Mori. 1992. Comparison of various biological activities of stereoisomers of methyl jasmonate. Phytochemistry 31:1111-1114.

Li, W.X., O. Kodama, and T. Akatsuka. 1991. Role of oxygenated fatty acids in rice phytoalexin production. Agr. Biol. Chem. 55:1041-1047.

Lorbeth, R., C. Dammann, M. Ebneth, S. Amati, and J.J. Sánchez-Serrano. 1992. Promoter elements involved in environmental and developmental control of potato proteinase inhibitor II expression. Plant J. 2:477-486.

Major, R.T., P. Marchini, and T. Sproston. 1960. Isolation from Ginkgo biloba L. of an inhibitor of fungus growth. J. Biol. Chem. 235:3298-3299.

Mason, H.S., D.B. Dewald, R.A. Creelman, and J.E. Mullet. 1992 . Coregulation of soybean vegetative storage protein gene expression by methyl jasmonate and soluble sugars. Plant Physiol. 98:859-867.

Masui, H. and M. Kojima. 1990. Lipid peroxidation and its role in taro tubers infected by Ceratocystis fimbriata. Agr. Biol. Chem. 54:1689-1695.

Masui, H., T. Kondo, and M. Kojima. 1989. An antifungal compound, 9,12,13trihydroxy-(E)-10-octadecenoic acid, from Colocasia antiquorum inoculated with Ceratocystis fimbriata. Phytochemistry 28:2613-2615.

Matoba, T., et al. 1989. n-Hexanol formation from n-hexanal by enzyme action in soybean extracts. J. Food Sci. 54:1607-1610.

Matsui, K., T. Hiromitu, T. Kajiwara, T. Kakuno, and A. Hatanaka. 1991. Fatty acid hydroperoxide cleaving enzyme, hydroperoxide lyase, from tea leaves. Phytochemistry 30:2109-2113.

Matsui, K., Y. Shibata, T. Kajiwara, and A. Hatanaka. 1989. Separation of $13-$ and 9-hydroperoxide lyase activities in cotyledons of cucumber seedlings. Z. Naturforsch. 44c:883-885.

Matsuki, T., H. Tazaki, T. Fujimori, and T. Hogeisu. 1992. The influences of jasmonic acid methyl ester on microtubules in potato cells and formation of potato tubers. Biosci. Biotechnol. Biochem. 56:1329-1330.

Melan, M.A., et al. 1993. An Arabidopsis thaliana lipoxygenase gene can be induced by pathogens, abscisic acid, and methyl jasmonate. Plant Physiol. 101:441-450.

Mohri, S., Y. Endo, K. Matsuda, K. Kitamura, and K. Fujimoto. 1990. Physiological effects of soybean seed lipoxygenases on insects. Agr. Biol. Chem. 54:2265-2270.

Mueller, M.J., W. Brodschelm, E. Spannagl, and M.H. Zenk. 1993. Signaling in the elicitation process is mediated through the octadecanoid pathway leading to jasmonic acid. Proc. Natl. Acad. Sci. USA 90:7490-7494.

Nandi, B. and N. Fries. 1976. Volatile aldehydes, ketones, esters and terpenoids as preservatives against storage fungi in wheat. Z. Pflanzenkrankh. Pflanzenschutz 83:284-294.

Natarajan, V., W.M. Scribner, and M.M. Taher. 1993. 4-Hydroxynonenal, a metabolite of lipid peroxidation, activates phospholipase D in vascular endothelial cells. Free Radical Biol. Med. 15:365-375.

Nishida, R., T.E. Acree, and H. Fukami. 1985. Optical resolution of methyl jasmonate and methyl epijasmonate. Agr. Biol. Chem. 49:769-772.

Nojiri, H., et al. 1992. Qualitative and quantitative analysis of endogenous jasmonic acid in bulbing and non-bulbing onion plants. Plant Cell Physiol. 33:1225-1231.

Nugteren, D.H., R.K. Beerthuis, and D.A. van Dorp. 1966. The enzymic conversion of all-cis 8,11,14-eicosatrienoic acid into prostaglandin $\mathrm{E}_{1}$. Rec. Trav. Chim. Pays-Bas 85:405-419.

O'Connor, D.E., E.D. Mihelich, and M.C. Coleman. 1984. Stereochemical course of the autoxidative cyclization of lipid hydroperoxides to prostaglandin-like bicyclo endoperoxides. J. Amer. Chem. Soc. 106:3577-3584.

Ohta, H., et al. 1990. The occurrence of lipid hydroperoxide-decomposing activities in rice and the relationship of such activities to the formation of antifungal substances. Plant Cell Physiol. 31:1117-1122.

Ohta, H., et al. 1991. A lipoxygenase pathway is activated in rice after infection with the rice blast fungus Magnaporthe grisea. Plant Physiol. 97:94-98.

Peña-Cortés, H., T. Albrecht, S. Prat, E.W. Weiler, and L. Willmitzer. 1993. Aspirin prevents wound-induced gene expression in tomato leaves by blocking jasmonic acid biosynthesis. Planta 191:123-128.

Peña-Cortés, H., X. Liu, J.S. Serrano, R. Schmid, and L. Willmitzer. 1992. Factors affecting gene expression of patatin and proteinase-inhibitor-II gene families in detached potato leaves: Implications for their co-expression in developing tubers. Planta 186:495-502.
Phillips, D.R., J.A. Matthew, J. Reynolds, and G.R. Fenwick. 1979. Partial purification and properties of a cis-3:trans-2-enal isomerase from cucumber fruit. Phytochemistry 18:401-404.

Ranjan, R. and S. Lewak. 1992. Jasmonic acid promotes germination and lipase activity in nonstratified apple embryos. Physiol. Plant. 86:335-339.

Reinbothe, S., C. Reinbothe, C. Heintzen, C. Seidenbecher, and B. Parthier. 1993a. A methyl jasmonate-induced shift in the length of the 5' untranslated region impairs translation of the plastid $r b c L$ transcript in barley. EMBO J. 12:1505-1512.

Reinbothe, S., C. Reinbothe, J. Lehmann, and B. Parthier. 1992. Differential accumulation of methyl jasmonate-induced mRNAs in response to abscisic acid and desiccation in barley (Hordeum vulgare). Physiol. Plant. 86:4956.

Reinbothe, S., C. Reinbothe, and B. Parthier. 1993b. Methyl jasmonateregulated translation of nuclear-encoded chloroplast proteins in barley (Hordeum vulgare L. cv. Salome). J. Biol. Chem. 268:10606-10611.

Rickauer, M., A. Bottin, and M.-T. Esquerré-Tugayé. 1992. Regulation of proteinase inhibitor production in tobacco cells by fungal elicitors, hormonal factors and methyl jasmonate. Plant Physiol. Biochem. 30:579584.

Sanz, L.C., J.C. Fernández-Maculet, E. Gómez, B. Vioque, and J.M. Olías. 1993. Effect of methyl jasmonate on ethylene biosynthesis and stomatal closure in olive leaves. Phytochemistry 33:285-289.

Schildknecht, H. and G. Rauch. 1961. The chemical nature of "air-borne phytocide" of leafy plants especially of Robinia pseudacacia II. Communication about defensive substances of plants. Z. Naturforsch. 16b:422429.

Schweizer, P., R. Gees, and E. Mösinger. 1993. Effect of jasmonic acid on the interaction of barley (Hordeum vulgare L.) with the powdery mildew Erysiphe graminis f.sp. hordei. Plant Physiol. 102:503-511.

Sembdner, G. and B. Parthier. 1993. The biochemistry and the physiological and molecular actions of jasmonates. Annu. Rev. Plant Physiol. Plant Mol. Biol. 44:569-589.

Shimura, M., et al. 1983. Anti-conidial germination factors induced in the presence of probenazole in infected host leaves. III. Structural elucidation of substances A and C. Agr. Biol. Chem. 47:1983-1989.

Song, W.-C. and A.R. Brash. 1991. Purification of an allene oxide synthase and identification of the enzyme as a cytochrome P-450. Science 253:781-784.

Song, W.-C., C.D. Funk, and A.R. Brash. 1993. Molecular cloning of an allene oxide synthase: A cytochrome P450 specialized for the metabolism of fatty acid hydroperoxides. Proc. Natl. Acad. Sci. USA 90:8519-8523.

Staswick, P.E. 1992. Jasmonate, genes, and fragrant signals. Plant Physiol. 99:804-807.

Staswick, P.E., W. Su, and S.H. Howell. 1992. Methyl jasmonate inhibition of root growth and induction of a leaf protein are decreased in an Arabidopsis thaliana mutant. Proc. Natl. Acad. Sci. USA 89:6837-6840.

Szweda, L.I., K. Uchida, L. Tsai, and E.R. Stadtman. 1993. Inactivation of glucose-6-phosphate dehydrogenase by 4-hydroxy-2-nonenal. J. Biol.Chem. 268:3342-3347.

Urbasch, I. 1987. Transformation of trans-2-hexenal by Botrytis cinerea PERS. as detoxification mechanisms. Z. Naturforsch. 42c:64-68.

van den Berg, J.H. and E.E. Ewing. 1991. Jasmonates and their role in plant growth and development, with special reference to the control of potato tuberization: A review. Amer. Potato J. 68:781-794.

Vaughn, S.F. and H.W. Gardner. 1993. Lipoxygenase-derived aldehydes inhibit fungi pathogenic on soybean. J. Chem. Ecol. 19:2337-2345.

Vaughn, S.F. and E.C. Lulai. 1992. Further evidence that lipoxygenase activity is required for arachidonic acid-elicited hypersensitivity in potato callus cultures. Plant Sci. 84:91-98.

Vick, B.A. and D.C. Zimmerman. 1982. Levels of oxygenated fatty acids in young corn and sunflower plants. Plant Physiol. 69:1103-1108.

Vick, B.A. and D.C. Zimmerman. 1983. The biosynthesis of jasmonic acid: A physiological role for plant lipoxygenase. Biochem. Biophys. Res. Commun. 111:470-477.

Vick, B.A. and D.C. Zimmerman. 1986. Characterization of 12-oxophytodienoic acid reductase in corn. The jasmonic acid pathway. Plant Physiol. 80:202-205.

Weiler, E.W. 1993. Octadecanoid-derived signaling molecules involved in touch perception in a higher plant. Bot. Acta 106:2-4.

Weiler, E.W., et al. 1993. Evidence for the involvement of jasmonates and their octadecanoid precursors in the tendril coiling response of Bryonia dioica. Phytochemistry 32:591-600.

Wurzenberger, M. and W. Grosch. 1984. Stereochemistry of the cleavage of the 10-hydroperoxide isomer of linoleic acid to 1-octen-3-ol by a hydroperoxide lyase from mushrooms (Psalliota bispora). Biochim. Biophys. Acta 795:163-165.

Yamagishi, K., et al. 1993. Jasmonic acid-inducible gene expression of a Kunitz-type proteinase inhibitor in potato tuber disks. Plant Mol. Biol. 21:539-541. 
Yoshihara, T., et al. 1989. Structure of a tuber-inducing stimulus from potato leaves (Solanum tuberosum L.). Agr. Biol. Chem. 53:2835-2837.

Zeringue, Jr., H.J. and S.P. McCormick. 1989. Relationships between cotton leaf-derived volatiles and growth of Aspergillus flavus. J. Amer. Oil Chem. Soc. 66:581-585.

Zeringue, Jr., H.J. and S.P. McCormick. 1990. Aflatoxin production in cultures of Aspergillus flavus incubated in atmospheres containing selected cotton leaf-derived volatiles. Toxicon 28:445-448.
Zimmerman, D.C. 1966. A new product of linoleic acid oxidation by a flaxseed enzyme. Biochem. Biophys. Res. Commun. 23:398-402.

Zimmerman, D.C. and C.A. Coudron. 1979. Identification of traumatin, a wound hormone, as 12-oxo-trans-10-dodecenoic acid. Plant Physiol. 63:536-541.

Zimmerman, D.C. and P. Feng. 1978. Characterization of a prostaglandin-like metabolite of linolenic acid produced by a flaxseed extract. Lipids 13:313-316.

\title{
Peroxidative Activity of Apple Peel in Relation to Development of Poststorage Disorders
}

\author{
Zhanyuan Du and William J. Bramlage \\ Department of Plant and Soil Sciences, University of Massachusetts, Amherst, MA 01003
}

Lipid peroxidation is a factor in the development of plant tissue senescence (Thompson et al., 1991), and in responses to physiological stresses such as chilling (Parkin and Kuo, 1989). Apple (Malus domestica Borkh.) fruit are commonly stored for long periods at low temperature, and during this time a variety of disorders can develop, only some of which appear to be uniquely associated with senescence. Many apple cultivars are chilling sensitive, although several months near $0 \mathrm{C}$ are required for symptoms to develop (Bramlage and Meir, 1990). During this time, both senescence and chilling injury can occur, and an interaction between these conditions could contribute to the development of certain disorders.

Superficial scald develops on the surface of certain apple cultivars following long-term storage near $0 \mathrm{C}$. The scald results from peroxidation of the sesquiterpene $\propto$-farnesene in fruit peel, producing conjugated trienes that presumably perturb membrane lipids under certain conditions, causing disruption, discoloration, and death of surface cells (Anet, 1974; Huelin and Coggiola, 1970a). The disorder is usually controlled by applying the antioxidant diphenylamine (DPA) to fruit before placing them in storage. DPA inhibits the oxidation of $\propto$-farnesene (Huelin and Coggiola, 1970b).

We recently presented evidence that only a portion of the conjugated trienes are positively correlated with scald development, while another portion is negatively correlated with it (Du and Bramlage, 1993), and that ethylene is fundamentally involved in development of conditions that help determine scald development (Du and Bramlage, 1994). Ethylene production is mediated by free radicals (Gardner and Newton, 1987), and ethylene regulates many aspects of fruit ripening and senescence (Abeles et al., 1992). Also, DPA treatment affects ethylene production, respiration, and enzyme activity (Baker, 1963; Lurie et al., 1989), as well as reducing $\propto$-farnesene oxidation in apple peel. Since lipid peroxidation is a prominent factor in apple senescence (Feys, 1985; Feys et al., 1980), we proposed that lipid peroxidation products may contribute to conditions that determine scald development, and possibly to symptom expression itself. To investigate this hypothesis, we sampled apple fruit under a variety of conditions related to scald development, and assayed them for some general peroxidation products, and for activities of enzymes that are important in controlling the accumulation of peroxidation products in plant tissues. We now detail this work as part of this workshop.

\section{Plant materials}

Investigations occurred over 3 years using fruit grown under normal orchard conditions at the Univ. of Massachusetts Horticultural Research Center, Belchertown.

The cost of publishing this paper was defrayed in part by the payment of page charges. Under postal regulations, this paper therefore must be hereby marked advertisement solely to indicate this fact.
On 26 Sept. and 10 Oct. 1990, $\approx 200$ 'Cortland' and 'Delicious' apples, respectively, were harvested from each of three single-tree replications at commercial maturity. Before storage, half of the harvested fruit of each cultivar was dipped in fungicide [ $227 \mathrm{~g}$ of $50 \%$ methyl 1-(butyl carbamoyl)-2-benzimidazocarbamate (benlate) and $454 \mathrm{~g}$ of $3 \mathrm{a}, 4,7,7 \mathrm{a}$-tetrahydro-2-[(trichloromethyl)thiol]-1- $H$-isoindole1,3(2H)-dione (captan) per 400 liters of water] as control, and the other half was dipped in $2 \mathrm{~g}$ DPA/liter plus fungicide. All fruit then were stored at $0 \mathrm{C}$ in air. Ten-fruit samples were taken from each replicate at harvest and at every 4 weeks during storage, up to a maximum of 16 weeks. Sampled fruit were peeled, and the peel was cut into small pieces, mixed, frozen immediately in dry ice, and stored at $-25 \mathrm{C}$ for subsequent analyses. Scald incidence on the remaining fruit was evaluated visually after 16 weeks at $0 \mathrm{C}$ plus 7 days at 20C. No scald had developed on 'Delicious' at this time, so fruit were returned to storage for an additional 8 weeks plus 7 days at 20C for a second scald evaluation.

On 30 Sept. 1991, $\approx 400$ 'Empire' fruit were harvested from each of four single-tree replications and stored at $0 \mathrm{C}$ in air for 24 weeks. Tenfruit samples were taken at 4-week intervals, peeled, and frozen for analyses as described above. After 24 weeks at $0 \mathrm{C}$, senescent breakdown was present in some fruit. Ten fruit with the disorder and 10 fruit free of it were selected from each replication. Peel was taken from disorder-free fruit as above, but diseased fruit peel was taken only from areas with symptoms. Peel was frozen for assay as above.

On 9 Sept. 1992, $\approx 200$ 'Cortland' fruit were harvested from each of four single-tree replications and stored at $0 \mathrm{C}$ for 20 weeks. Stored fruit then were transferred to $20 \mathrm{C}$ for 7 days and evaluated for scald development. Fruit within each replication then were sorted into three groups according to their scald intensity, i.e., no scald; $1 \%$ to $33 \%$ of fruit surface; and $>33 \%$ of fruit surface affected with scald. Ten fruit without senescent breakdown were selected randomly from each group, peeled, and frozen for analyses.

\section{Assays of lipid peroxidation products}

Extraction. Ten grams of frozen peel were homogenized in a blender with $50 \mathrm{ml}$ of cold acetone for $3 \mathrm{~min}$ and filtered through Whatman no. 4 paper. The filtrate was brought to $75 \mathrm{ml}$ with water and kept at $4 \mathrm{C}$ under refrigeration for measurements.

Measurements. Two groups of products of lipid peroxidation were measured in the present study. The thiobarbituric acid-reactive substances (TBARS) were measured using the thiobarbituric acid assay modified to adjust for the high sugar content of fruit [expressed as nmoles of malondialdehyde (MDA) per gram of fresh weight; Du and Bramlage (1992)]. Total peroxides were determined according to Brennan and Frenkel (1977), modified as follows: $1 \mathrm{ml}$ of properly diluted extract and $4 \mathrm{ml}$ of water were added to $1 \mathrm{ml}$ of titanium reagent ( $20 \%$ titanic tetrachloride in concentrated $\mathrm{HCl}, \mathrm{v} / \mathrm{v})$. After mixing and 